Postgrad. MED. J., (1966), 42, 314

\title{
CARDIAC ARREST IN THE WARD
}

\author{
Clive H. Young, M.R.C.S., L.R.C.P., \\ Surgical Registrar, Dreadnought Seamen's Hospital, London, S.E.10.
}

DESPITE the fact that much has been written over the years in the medical and lay press about the treatment of cardiac arrest, it is difficult to find in the literature a regime which can be easily and rapidly undertaken by junior hospital staff and nurses in hospitals outside the main teaching and cardiac centres. This paper sets out a regime which has proved workable in a small hospital and describes the equipment used.

\section{General Considerations}

Cardiac arrest may occur anywhere at any time so that it is essential that all hospital staff be trained in its treatment, that there be an efficient alarm system and that the equipment be within easy reach. "Success will only be achieved if a series of previously rehearsed steps can be put into operation almost as a reflex". (Milstein, 1963).

All nurses are trained in external cardiac massage (Kouwenhoven, Jude and Knickerbocker, 1960) and mouth-to-mouth ventilation (Brook, Brook and Wyant, 1962) on a ResusciAnne training model and are made familiar with the resuscitation trolley and its contents. Each ward and department has a sheet of instructions for dealing with cardiac arrest and each ward sister rehearses this regularly with nurses. Medical staff are instructed in treatment as soon as they arrive at the hospital.

It is essential that medical staff be summoned quickly but the alarm system used must depend on the facilities available in individual hospitals.

All equipment is contained on one trolley which is centrally based and is never locked up. It can arrive at the most distant bed in under five minutes.

\section{Equipment}

Each ward has a certain amount of emergency equipment such as a Brook airway, a board for putting under the patient's chest to obviate the displacement of the mattress during external cardiac massage and a tray with drugs useful in an emergency.

All equipment should be mobile and in this hospital is mounted on a converted kitchen trolley (Fig. 1) which has been so wired that it provides four $5 \mathrm{amp}$. outlets by plugging

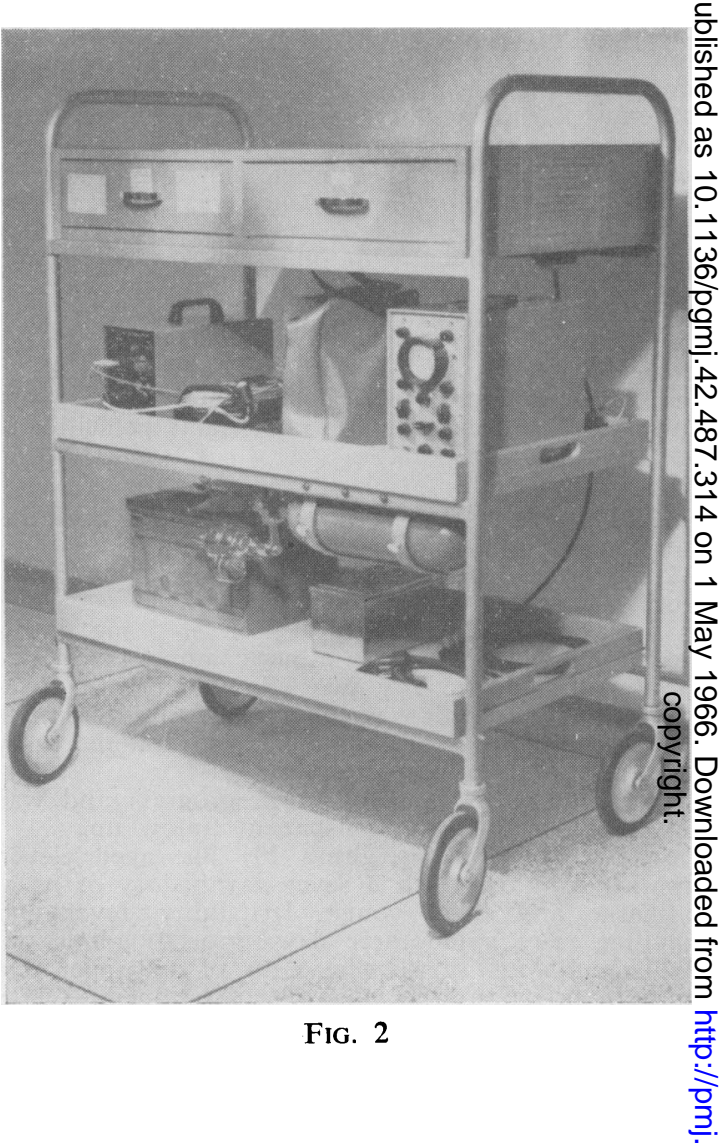

the cable from the trolley into the wall with a fused plug (Fig. 2). On the trolley is an. adaptor which ensures that the trolley mays be used in any room in the hospital.

The trolley has two drawers on the front, the left one divided into three compartments, and one drawer for spares on the back. There is. a working surface on the top and two shelves for storing apparatus below. A list of content is given below.

Left drawer:-

First compartment

Intravenous canulae

Giving set

Syringes 20, 10, 5, $2 \mathrm{ml}$.

Needles 1, 12, 17, intracardiac

Swabs in spirit

Scissors

Tracheal suction catheters 
Second compartment

Connection from endotracheal

tube to Ambu bag

Guedel airways

Dry swabs

Strapping

Straight laryngoscope blade

Child's laryngoscope iblade

Third compartment

Endotracheal tubes with connections

Laryngoscope with curved adult

blade

Lubricating jelly

Syringe for endotracheal tube cuff

Artery forceps for cuff

Right drawer-drugs:-

Sodium bicarbonate $8.4 \%$

Calcium Gluconate $10 \%$

Adrenaline 1/10,000

Procaine Amide

Potassium Chloride 4\%

Metaraminol 1\%

Mephentarmine Sulphate

Hydrocortisone $100 \mathrm{mg}$.

Nalorphine

Digoxin $0.5 \mathrm{mg}$ ampoules

Noradrenaline 1/1000

Sucrose $50 \%$

Ureaphil $80 \mathrm{~g}$

Thiopentone sodium $1 \mathrm{~g}$.

Promazine Hydrochloride

Pyrogen-free water

Ampoule files

Back drawer:-

Contains spares of expendable items.

Upper shelf :-

Defibrillator (Cardiac Recorders)

Electrocardiascope (Rank Medical Equipment)

Ambu bag, face masks and Oxygen tube (in separate bag)

Torch

Electrode jelly

Lower shelf:-

Tracheostomy drum with standard contents

Adaptor for mains plug

Oxygen cylinder (72 gallons)

Cut-down set

\section{Treatment}

Cardiac resuscitation in this hospital is based on the plan set out below which fits onto a sheet of foolscap and is displayed in all wards and departments and is given to all medical staff on arrival. However "the place for such a plan is in the mind" (Milstein, 1963) since there is no time in an emergency for reference to the written word.

\section{CARDIAC ARREST}

Cardiac arrest means a sudden failure of cardiac output resulting from ventricular asystole, tachycardia or fibrillation and causing failure of cerebral circulation.

Diagnosis. Sudden loss of consciousness with absent carotid pulses. (Usually accompanied by

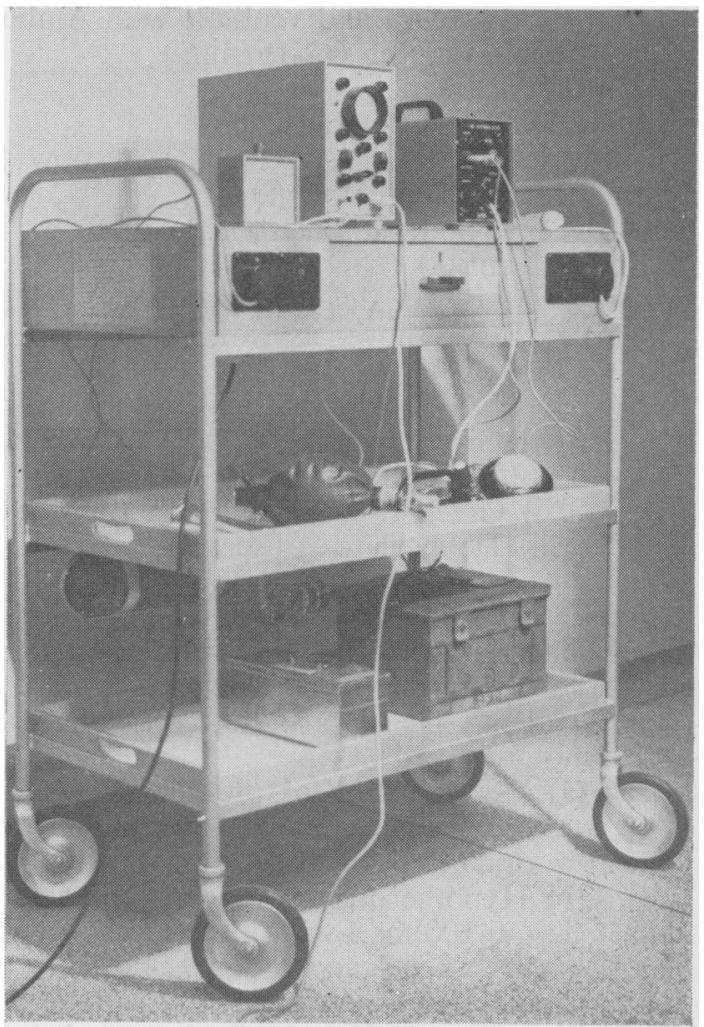

FiG. 2

cessation of respiration and dilated pupils with no light reflex).

Treatment must be instituted immediately if cerebral damage is to be avoided during the period of circulatory arrest.

\section{Treatment}

Phase I (to be started immediately by medical/ nursing staff present at the time of arrest).

1. Thump the middle of the sternum once (this may start the heart)

2. Start External Cardiac Massage (must be done on a resistant surface at $60 / \mathrm{min}$.)

3. Start Positive Pressure Respiration (12$15 / \mathrm{min}$.)

(a) mouth to mouth (neck must be extended)

(b) with Brook airway

(c) with Ambu bag, face mask and Guedel airway (on arrival)

4. Raise foot of bed and remove head of bed

5. Send for Resuscitation Trolley

6. Call Medical Staff

Phase II (Medical Staff)

1. Continue External Cardiac Massage $(60 / \mathrm{min}$.) 
2. Intubate trachea and ventilate with Ambu bag with Oxygen (12-15/min.)

3. Suck out trachea

4. Connect electrocardiascope

5. Put up drip (may have to be a cut dowr)

Phase III (definitive treatment)

1. Give i.v. Sodium Bicarbonate (5-10 g. $=$ 60-120 mEq.)

2. Give i.v. $10 \%$ Calcium Gluconate $(10 \mathrm{ml}$.)

3. (a) if ECG shows asystole, continue as above

(b) if EOG shows ventricular fibrillation

(i) Give i.v. 1/10,000 adrenaline (5-10 ml.)

(ii) Give i.v. procaine amide (0.5-1 g.)

(iii) Defibrillate (disconnect electrocardiascope)

Phase IV (supportive treatment)

1. Connect patient to the Barnet Ventila!or

2. Noradrenaline may be needed $(16 \mathrm{ml}$./1.)

3. If patient's heart starts but consciousness is not regained

(a) the reduction of presumptive cerebral oedema by i.v. urea (40-80 g.) or $50 \%$ sucrose $(40 \mathrm{ml}$.)

(b) Hypothermia by i.v. promazine (50-100 mg.) with the application of wet sheets and a fan

should be considered

4. If fits occur give small doses of i.v. thiopentone.

No mention is made of a pacemaker in the regime, as we do not have one in this hospital, but, if available, the instructions for its use may be inserted into Phase III, 3 (a).

The Barnet Ventilator (Phase IV) is not carried on the resuscitation trolley but is quickly available should it be required.

\section{Discussion}

Many signs of cardiac arrest are described but the cardinal feature is absence of the pulse in a large artery. Others may be difficult to elicit or may be changed by drugs.

The primary object of treatment is not $\mathrm{soc}_{c}$ much to restore the heart beat as to ensure $=$ that the brain receives oxygenated blood within three minutes of cardiac arrest, as irreversiblec brain damage will otherwise ensue. This is carried out by ensuring a clear airway, by $\frac{\vec{p}}{\overrightarrow{0}}$ positive pressure respiration and by externa $\stackrel{\mathbb{Q}}{\Omega}^{2}$ cardiac massage. The regime described can beos carried out by all members of the medical staffwho are trained in all the techniques required. We have no resident anaesthetist and the team $\vec{\omega}$ is coordinated by the medical or surgicalo registrar.

The phasing of procedure is helpful in that all items in a phase should be completed before moving on to the next one. All proce- $t$ dures should be performed as simultaneous' as is practicable; this is especially true of Phase $e_{-}^{\omega}$ I which depends mainly on the nursing staff.

\section{Summary}

A phased regime for the treatment of cardiac arrest in the wards of a smaller general hospitak is set out and discussed. The necessary equip $\overrightarrow{0}$ ment and a suitable trolley have been describato

I would like to thank Dr. Ronald Hartley a⿳亠丷⿵冂丶 Dr. Eric Goldsmith for their advice and encourages ment in the preparation of this paper and the medica and nursing staff of the hospital for their help in working out the regime. My thanks are also due to Mr. Richard Watts for the photographs. I amo most grateful to Mr. B. B. Milstein and his pub $\overrightarrow{7}$ lishers, Lloyd-Luke of London, for permission too reproduce passages from their book "Cardiac Arres? and Resuscitation".

\section{REFERENCES}

Brook, M. H., Brook, J., and Wyant, G. M. (1962) Emergency Resuscitation, Brit. med. J., ii, 1564.

KOUWENHOVEN, W. B., JUDE, J. R., and KNICKER BOCKER, G. G. (1960): Closed Chest Cardiac. Massage, J. Amer. med. Ass., 173, 1064.

MilsteIN, B. B. (1963): Cardiac Arrest and Resusci tation. London: Lloyd-Luke. 